\title{
Nucleated Thrombocyte Count
}

National Cancer Institute

\section{Source}

National Cancer Institute. Nucleated Thrombocyte Count. NCI Thesaurus. Code

C111283.

The determination of the amount of nucleated thrombocytes present in a sample. This is typically measured in birds and other non-mammalian vertebrates. 